\title{
Polyvalent Degenerate Oligonucleotides Reverse Transcription-Polymerase Chain Reaction: A Polyvalent Detection and Characterization Tool for Trichoviruses, Capilloviruses, and Foveaviruses
}

\author{
Xavier Foissac, Laurence Svanella-Dumas, Pascal Gentit, Marie-Josée Dulucq, Armelle Marais, and Thierry Candresse
}

First, second, fourth, fifth, and sixth authors: Equipe de Virologie, UMR GD2P, IBVM, INRA and University Victor Ségalen Bordeaux2, BP81, 33883 Villenave d'Ornon Cedex, France; and third author: Laboratoire de Virologie, Ctifl, Centre de Lanxade, BP21, 24130 La Force, France.

Accepted for publication 7 February 2005.

\section{ABSTRACT}

Foissac, X., Svanella-Dumas, L., Gentit, P., Dulucq, M.-J., Marais, A., and Candresse, T. 2005. Polyvalent degenerate oligonucleotides reverse transcription-polymerase chain reaction: A polyvalent detection and characterization tool for trichoviruses, capilloviruses, and foveaviruses. Phytopathology 95:617-625.

A polyvalent nested reverse transcription-polymerase chain reaction (RT-PCR) test using degenerate primers containing inosine (polyvalent degenerate oligonucleotides [PDO]) was developed for filamentous fruit tree viruses belonging to the genera Trichovirus, Capillovirus, and Foveavirus. The 362-bp product was amplified from nucleic acid extracts obtained from Prunus and Malus leaf samples. All the viruses targeted were detected, demonstrating the polyvalence of the test. The variability of a collection of Apple chlorotic leaf spot virus isolates was analyzed using the sequence of the PDO RT-PCR amplified cDNAs. The technique was also used to screen stone fruit materials infected with known agents or with virus-like graft-transmissible diseases of unknown etiology. The results obtained further validated the broad specificity of the assay, with positive amplification obtained for uncharacterized or partially characterized viruses associated with cherry and peach disorders. Sequencing the amplified PCR products either directly or after cloning allowed the identification of variants of known agents and the tentative identification of two new agents, a Trichovirus and a Foveavirus. In addition, sequence comparisons demonstrated that the sequence of the targeted region is phylogenetically informative and of predictive taxonomic value.
The past few years have seen a dramatic evolution in the taxonomy of plant viruses. This stems in part from the increased availability of genomic sequences for well-known agents and in part from the rapid rate at which new agents are being discovered and characterized. This steady increase in the number of known viral agents (48) added to the need to be able, in some case, to detect unknown agents has increased the complexity of viral diagnosis, in particular in certification and etiology studies. On the other hand, the availability of a wealth of genomic sequence information has led to the generally straightforward development of sequence-targeted detection assays based on the polymerase chain reaction (PCR) for many viruses (for a review see literature citation 4). An alternative but somewhat less developed strategy is the development of PCR-based assays using primers targeting conserved regions of viral genomes, thus allowing the simultaneous detection of a number of different viruses in a single PCR assay. Following the initial demonstration that degenerate primers can amplify a range of potyviruses (29), extensive efforts in a number of laboratories have led to the development of numerous broad-spectrum PCR assays allowing the amplification of a few viruses or of even most or all members of a genus, including, for example, closteroviruses (26), tymoviruses and marafiviruses (41), mastreviruses (49), begomoviruses $(3,38)$, cucumoviruses (7), carmoviruses (34), badnaviruses (44), tobamoviruses (10), or potyviruses $(8,37)$. Despite their potential usefulness, there are, however, few examples of primer pairs or PCR-based amplification assays with a specificity extending above the genus level, a

Corresponding author: T. Candresse; E-mail address: tc@bordeaux.inra.fr

DOI: 10.1094/PHYTO-95-0617

(C) 2005 The American Phytopathological Society notable exception being the development of assays to amplify all members of the family Potyviridae, including members of the genera Potyvirus, Macluravirus, Ipomovirus, Rymovirus, Tritimovirus, and Bymovirus $(6,17)$. An assay allowing the amplification of members of the family Comoviridae has also been reported (31).

The ability to amplify partial cDNA sequences from a whole group of plant viruses in a single assay has obvious applications in diagnostics because it offers cost-cutting possibilities by allowing the simultaneous detection of several agents in a single assay. It also has important potential application in the characterization of previously unknown or poorly known viral agents $(31,40$, $41,46)$, for the analysis of the molecular variability of viral agents (49), and for the evaluation of the phylogenetic relationships of poorly known viruses, genera, or higher order taxonomic groupings (18).

The recently approved family Flexiviridae (1) regroups a series of plant virus genera characterized by a clear common ancestry in their replication-associated proteins and coat proteins and by their flexuous, elongated particle morphology. It includes the genera Potexvirus, Carlavirus, Allexivirus, Capillovirus, Foveavirus, Trichovirus, and Vitivirus plus the new genus Mandarivirus and several related viruses not assigned currently to any genus, such as Banana mild mosaic virus (BanMMV) (13), Cherry green ring mottle virus (CGRMV) (52), Cherry necrotic rusty mottle virus (CNRMV) (39), Citrus leaf blotch virus (CLBV) (12), or Sugarcane striate mosaic-associated virus (SCSMaV) (45).

Many of the viruses involved are still poorly characterized and new agents belonging to the family are discovered every year. This comes in part from the fact that for several of the genera involved, natural hosts are in many cases woody perennial plants such as fruit trees while alternate herbaceous hosts are hard to 
find and viral particles are very difficult to obtain in purified form. This is especially true of a group of closely related genera including Trichovirus, Capillovirus, and Foveavirus, most members of which infect temperate fruit trees of the family Prunoidae (peach, apricot, plum, Japanese plum and Japanese apricot, and cherry) and the family Maloidae (apple, pear, and Japanese pear). Among the important fruit tree viruses involved are Apple chlorotic leaf spot virus (ACLSV) and Cherry mottle leaf virus (CMLV), which are members of the genus Trichovirus $(22,32)$, Apple stem grooving virus (ASGV) and Cherry virus A (CVA), which are members of the genus Capillovirus (25,51), and Apple stem pitting virus (ASPV) and Apricot latent virus (ALV), which are members of the genus Foveavirus $(24,33,35)$.

The development of a polyvalent nested reverse transcription (RT)-PCR test for the detection of tricho-, capillo-, and foveaviruses which can detect several other members of the family Flexiviridae is reported here. A preliminary account of the development of this technique has been published as conference proceedings (11). In addition to its potential applications in the diagnostic field, this assay can be used, in combination with sequence analysis, for the characterization and analysis of the phylogenetic affinities of known and unknown filamentous viruses belonging to these three plant virus genera and to some related taxonomic entities.

\section{MATERIALS AND METHODS}

Viral isolates. ACLSV isolates were part of a collection of stone fruit tree viruses propagated by grafting (chip budding) on GF305 peach seedlings. Peach mosaic virus (PcMV) and CMLV (from D. James, Centre for Plant Health, Canadian Food Inspection Agency, Sidney, BC, Canada), Plum pox-like virus (PPLV) $(20,23)$ (from A. Hadidi, USDA, Beltsville, MD), and samples from a collection of temperate stone fruit tree diseases of unknown etiology kept at the CTIFL center of Lanxade (France) were similarly propagated on GF305 seedlings. All plants were kept under standard greenhouse conditions. The ASPV- and/or ASGV-infected apple and tobacco leaf samples were provided by J. Kummert (Faculté des Sciences Agronomiques de Gembloux, Belgium). In addition, all isolates of cherry viruses (some of which were provided by M. Rott and W. Jelkmann, BBA, Institut fur Pflanzenschutz im Obstbau, Dossenheim, Germany) or of cherry diseases of unknown etiology were grafted on sweet cherry cv. Sam under orchard conditions at CTIFL Lanxade.

Nucleic acid extractions. Total nucleic acids (TNA) were extracted from healthy or infected plant samples using one of two silica-capture-based extraction procedures modified from the procedure of Boom et al. (2). The first procedure was generally used, but the second one (M. Rott, personal communication) was preferred for apple samples.

Extraction procedure 1. Leaves $(0.5 \mathrm{~g})$ were ground in $2 \mathrm{ml}$ of phosphate-buffered saline (PBS)-Tween-PVP-Dieca (PBS buffer [137 mM NaCl, $3 \mathrm{mM} \mathrm{KCl}, 1.5 \mathrm{mM} \mathrm{KH_{2 }} \mathrm{PO}_{4}$, and $8 \mathrm{mM}$ $\mathrm{Na}_{2} \mathrm{HPO}_{4}, \mathrm{pH}$ 7.2] supplemented with $0.05 \%$ Tween $20,20 \mathrm{mM}$ sodium diethyldithiocarbamate, and $2 \%$ polyvinylpyrrolidone (PVP) molecular weight [MW] 25,000) and the homogenate was cleared by a 10 min centrifugation at $13,000 \times g$. Twenty microliters of $10 \%$ sodium dodecyl sulfate was added to $200 \mu \mathrm{l}$ of supernatant and transferred to a fresh tube, and the mixture was incubated for $15 \mathrm{~min}$ at $55^{\circ} \mathrm{C}$. One hundred microliters of $3 \mathrm{M}$ potassium acetate was then added with thorough mixing followed by a $5 \mathrm{~min}$ incubation on ice. After centrifugation at $13,000 \times g$ for $5 \mathrm{~min}$, the supernatant was transferred to a new tube and mixed with $700 \mu \mathrm{l}$ of $6 \mathrm{M} \mathrm{NaI}$ (prepared in $1.87 \% \mathrm{Na}_{2} \mathrm{SO}_{3}$ ) and $10 \mu \mathrm{l}$ of an autoclaved suspension of silica powder (SigmaAldrich, Saint-Quentin Fallavier, France) in sterile water (1 $\mathrm{g}$ of silica powder per $\mathrm{ml}, \mathrm{pH}$ adjusted to 2.0). Following incubation at room temperature for $10 \mathrm{~min}$ with intermittent shaking and centrifugation at $5,000 \times g$ for $1 \mathrm{~min}$, the silica pellet was washed twice by resuspension in $0.5 \mathrm{ml}$ of washing solution $(20 \mathrm{mM}$ Tris [pH 7.5], $1 \mathrm{mM}$ EDTA, $100 \mathrm{mM} \mathrm{NaCl}$, and $50 \%$ ethanol). The washed pellet was dried briefly and TNA were eluted by resuspending in $400 \mu \mathrm{l}$ of nuclease-free water and incubating for $5 \mathrm{~min}$ at $50^{\circ} \mathrm{C}$. The silica was collected by centrifugation at $13,000 \times g$ for $2 \mathrm{~min}$ and $300 \mu \mathrm{l}$ of the eluted TNA sample was transferred to a new tube and stored at $-20^{\circ} \mathrm{C}$ until used.

Extraction procedure 2 (for apple samples). This procedure was similar to the one described previously, with the following differences. Plant samples were homogenized $(0.5 \mathrm{~g}$ in $5 \mathrm{ml})$ in grinding buffer ( $4 \mathrm{M}$ guanidine thiocyanate, $0.2 \mathrm{M}$ sodium acetate, $25 \mathrm{mM}$ EDTA, $1 \mathrm{M}$ potassium acetate, 2.5\% PVP MW 40,000 , and $1 \% \beta$-mercaptoethanol). One hundred microliters of $10 \% \mathrm{~N}$ lauroyl sarkosyl was added to $500 \mu \mathrm{l}$ of clarified homogenate and incubated for $10 \mathrm{~min}$ at $70^{\circ} \mathrm{C}$ followed by $5 \mathrm{~min}$ on ice. After centrifugation at $13,000 \times g$ for $10 \mathrm{~min}, 300 \mu \mathrm{l}$ of the supernatant was mixed with $300 \mu \mathrm{l}$ of $6 \mathrm{M} \mathrm{NaI}, 150 \mu \mathrm{l}$ of $95 \%$ ethanol, and $25 \mu \mathrm{l}$ of autoclaved silica powder suspension. After washing the pellet in half-strength washing buffer $(10 \mathrm{mM}$ Tris [pH 7.5], $0.5 \mathrm{mM}$ EDTA, $50 \mathrm{mM} \mathrm{NaCl}$, and $50 \%$ ethanol), the TNA were eluted by resuspending the washed pellet in $200 \mu \mathrm{l}$ of nuclease-free water and incubating for $5 \mathrm{~min}$ at $70^{\circ} \mathrm{C}$.

Polyvalent degenerate oligonucleotides (PDO) nested RTPCR amplification. Each test was designed as a combined RTPCR assay with primers PDO-F1i, PDO-R3i, and PDO-R4i, from which an aliquot was used in a second nested PCR assay using primers PDO-F2i and PDO-R1i (Fig. 1). The first RT-PCR was carried out with $4 \mu \mathrm{l}$ of TNA extract in a final volume of $40 \mu \mathrm{l}$ (10 mM Tris- $\mathrm{HCl}[\mathrm{pH} 8.8], 50 \mathrm{mM} \mathrm{KCl}, 0.19 \%$ Triton X-100, $4 \mathrm{mM} \mathrm{MgCl} 2,200 \mu \mathrm{M}$ each dNTP, and $1 \mu \mathrm{M}$ each of primers PDO-F1i, PDO-R3i, and PDO-R4i) with 2 units of Avian myeloblastosis virus (AMV) RTase (Amersham Biosciences Europe GmbH, Orsay, France) and 1 unit of Taq DNA polymerase (Eurobio, Les Ullis, France). Reactions were incubated at $42^{\circ} \mathrm{C}$ for $45 \mathrm{~min}$ and, following a $3 \mathrm{~min}$ denaturation step at $95^{\circ} \mathrm{C}, 35$ amplification cycles $\left(30 \mathrm{~s}\right.$ at $95^{\circ} \mathrm{C}, 30 \mathrm{~s}$ at $42^{\circ} \mathrm{C}$, and $30 \mathrm{~s}$ at $72^{\circ} \mathrm{C}$ ) were performed. The nested PCRs were performed using $4 \mu \mathrm{l}$ of the first amplification reaction in a final volume of $40 \mu \mathrm{l}(10 \mathrm{mM}$ Tris- $\mathrm{HCl}$ [pH 8.8], $50 \mathrm{mM} \mathrm{KCl,} \mathrm{0.19 \%} \mathrm{Triton} \mathrm{X-100,} 4 \mathrm{mM}$ $\mathrm{MgCl}_{2}, 200 \mu \mathrm{M}$ each dNTP, and $1 \mu \mathrm{M}$ each of primers PDO-F2i and PDO-R1i) with 1 unit of Taq polymerase. After $3 \mathrm{~min}$ at $95^{\circ} \mathrm{C}$, the cycling scheme used ( 30 cycles) was $30 \mathrm{~s}$ at $95^{\circ} \mathrm{C}, 30 \mathrm{~s}$ at $42^{\circ} \mathrm{C}$, and $30 \mathrm{~s}$ at $72^{\circ} \mathrm{C}$. The volume of the first RT-PCR step transferred to the second nested PCR occasionally was reduced to $1 \mu \mathrm{l}$ to reduce the nonspecific amplification background. The final PCR product of $362 \mathrm{bp}$ was visualized under UV light after electrophoresis on ethidium bromide-stained $2 \%$ agarose gels.

Enzyme-linked immunosorbent assay and RT-PCR tests for the specific detection of ACLSV. For detection of ACLSV by enzyme-linked immunosorbent assay (ELISA), peach leaves $(0.5 \mathrm{~g})$ were homogenized in $2 \mathrm{ml}$ of PBS supplemented with $0.05 \%$ Tween 20 and 2\% PVP (MW 25,000) and the homogenate was clarified by centrifugation at $13,000 \times g$ for $10 \mathrm{~min}$. Then, the virus was detected by a standard double-antibody sandwich (DAS)ELISA test based on a polyclonal antiserum prepared against the P863 plum isolate of ACLSV (15). Specific RT-PCR detection of ACLSV was performed using $4 \mu \mathrm{l}$ of TNA samples obtained as described previously and using the A52-A53 primer pair and the amplification scheme described by Candresse et al. (5).

Cloning and sequence analysis. For the design of the PDO primers, complete genomic sequences were aligned at European Bioinformatics Institute (EBI) (available online by EBI) using CLUSTALW (43). PDO RT-PCR products were either directly sequenced or sequenced after cloning in pZERO-2 (Invitrogen, Cergy Pontoise, France) or in pGEM-T Easy Vectors (Promega, Charbonnières-les-Bains, France) when ambiguous sequences obtained from a PCR product indicated it contained a mixture of 
A

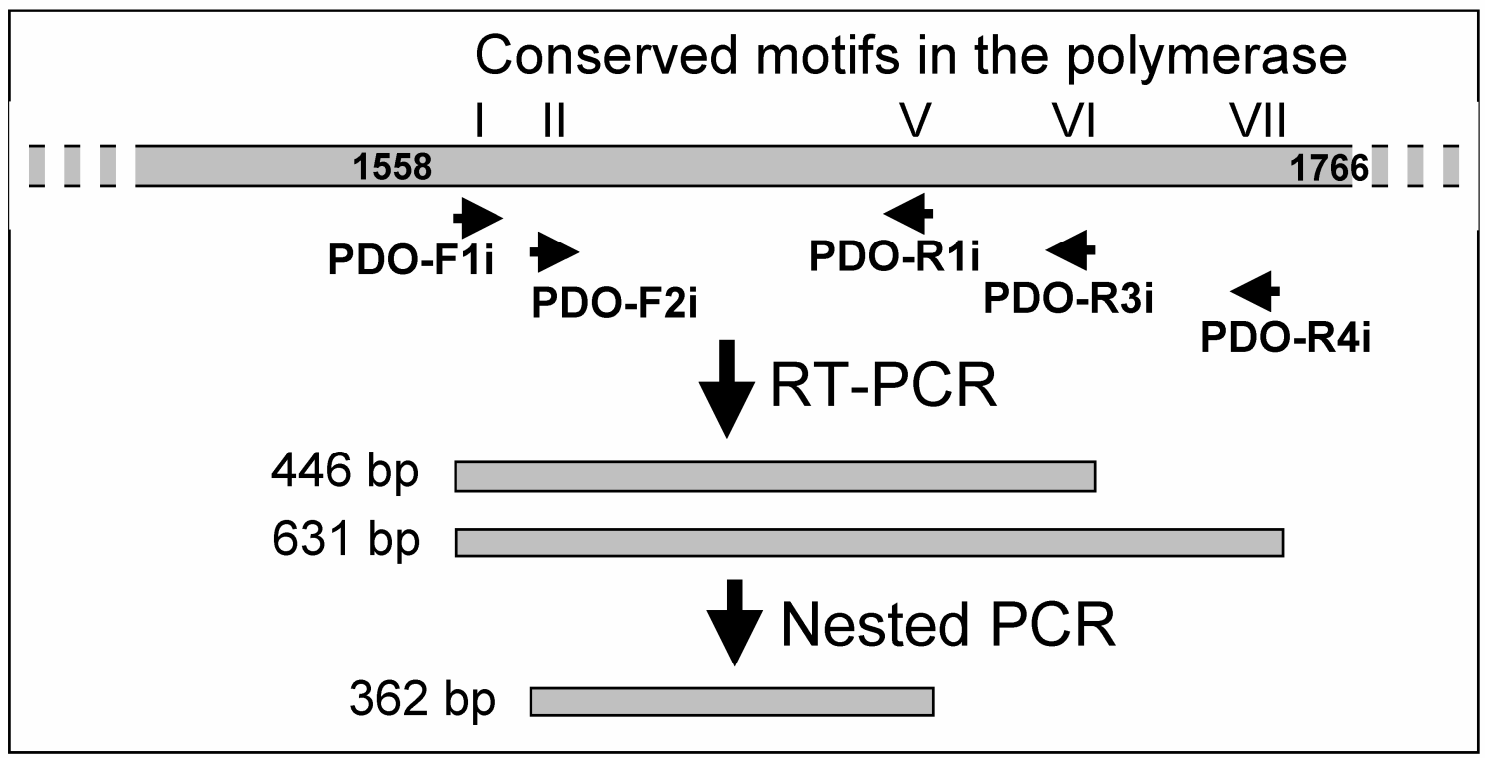

B

\begin{tabular}{|c|c|c|c|c|c|}
\hline & & MOTIF I & MOTIF II & & \\
\hline ACLSV & 1558 & LFMKSQLCTKEEK 1570//1575 & AKAGQTLACFPHKI & ILVEF 1592 & \\
\hline ASPV & & IFMKSQLCTKEDN & AKAGQTLACFQHSV & JLCRE & \\
\hline CGRMV & & IFMKSQLCTKFDN & AKAGQTLACEHHNV & JLCRL & \\
\hline CVA & & LFIKSQLLCTKKEK & AKAGQTLACFSHLI & ILCKF & \\
\hline \multirow[t]{3}{*}{ ASGV } & & LFMKSQYCTKEGK & AKAGQTLACFQHIV & JLFRF & \\
\hline & & 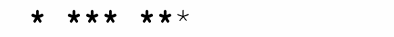 & 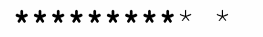 & *. & \\
\hline & \multicolumn{2}{|r|}{ MOTIF V } & & MOTIF VI & MOTIF VII \\
\hline ACLSV & \multirow[t]{6}{*}{1687} & \multirow{2}{*}{\multicolumn{2}{|c|}{ AIMRFTGEFSTFLFNTLANMVETFCRY $1713 / / 1722$}} & ICFAGDDMCA $1730 / / 1757$ & KVPMFCGWRL 1766 \\
\hline ASPV & & & & ICFAGDDMCA & ATPTFCGWGL \\
\hline CGRMV & & AIMRFTGEASTELFNTMANMLFTFLRY & AVMRFTGEAGTFLFNTLANMVFTEMRY & ICFAGDDMCA & TEPTFCGWRL \\
\hline CVA & & \multicolumn{2}{|c|}{ AIIRFTGEFCTFLFNTLTNMLFTEMKY } & ICFAGDDMCA & RSPTFCGWNL \\
\hline ASGV & & \multicolumn{2}{|c|}{ AIMRFTGEFCTFLFNTFANMLFTQLKY } & ILFAGDDMCS & KFPMFCGWYL \\
\hline & & 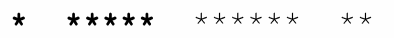 & $\star \star$ & $\star * \star * * * * *$ & $\star \star \star * * * *$ \\
\hline
\end{tabular}

C

PDO-F1i 5' TiTTYATKAARWSiCARYWiTGiAC 3' (Motif I)

PDO-F2i 5' GCYAARGCiGGiCARACiYTKGCiTG 3' (Motif II)

PDO-R1i 5' TCHCCWGTRAAiCKSATiAiiGC 3' (Motif V)

PDO-R3i 5' GCRCACATRTCRTCiCCiGCRAAiiA 3' (Motif VI)

PDO-R4i 5' ARiYiCCATCCRCARAAMiTiGG 3' (Motif VII)

Fig. 1. Principle of the polyvalent degenerate oligonucleotides (PDO) reverse transcription-polymerase chain reaction (RT-PCR) detection assay and sequence of the primers used. A, Schematic representation of the PDO RT-PCR assay. The top box represents the gene coding for the viral polymerase. The positions of the conserved amino-acid motifs are indicated above the bar and the positions on the Apple chlorotic leaf spot virus (ACLSV) protein are indicated within the box. The positions targeted by the various primers are indicated. For the first RT-PCR, primers PDO-F1i, PDO-R3i, and PDO-R4i are used, potentially producing two products of 446 and $631 \mathrm{bp}$, respectively. For the nested PCR, primers PDO-F2i and PDO-R1i are used, yielding a final product of 362 bp. B, Multiple alignment of the sequences of five conserved motifs targeted by the PDO primers in the polymerases of ACLSV (Trichovirus), Apple stem pitting virus (ASPV, Foveavirus), Cherry green ring mottle virus (CGRMV, unassigned Flexiviridae), Cherry virus A (CVA, Capillovirus), and Apple stem grooving virus (ASGV, Capillovirus). The positions are those of the border amino acids on the ACLSV P863 sequence. Asterisks indicate fully conserved amino acids. The amino acids encoded by the sequence targeted by the PDO primers are shown in bold. C, Sequence of the PDO primers. The degeneration codes used are as follows: N (A, T, G, or C); B (T, $\mathrm{G}$, or C); D (A, T, or G); H (A, T, or C); Y (C or T); R (A or G); S (G or C); W (A or T); K (G or T); M (C or A); and i (inosine). 
TABLE 1. List and origin of the Apple chlorotic leaf spot virus (ACLSV) isolates tested and accession numbers of the sequences of the cDNAs amplified by polyvalent degenerate oligonucleotides (PDO) reverse transcriptionpolymerase chain reaction

\begin{tabular}{|c|c|c|c|c|}
\hline Code & Isolate name $^{\mathrm{a}}$ & $\begin{array}{c}\text { Original } \\
\text { host }\end{array}$ & $\begin{array}{l}\text { Country } \\
\text { of origin }\end{array}$ & $\begin{array}{c}\text { Accession } \\
\text { no. }^{\mathrm{b}}\end{array}$ \\
\hline A1 & Commun A337 & Apricot & France & AF413929 \\
\hline A2 & Bulida 64 & Apricot & Spain & AF413930 \\
\hline A3 & Bulida B19 & Apricot & Spain & AF413931 \\
\hline A4 & Rouge du Roussillon D08 & Apricot & France & $\begin{array}{l}\text { AF413932 } \\
\text { AF413957 }\end{array}$ \\
\hline V1 & V804 Napoleon & Cherry & France & AF413933 \\
\hline V2 & Balaton (X99752) & Cherry & Hungary & AF413934 \\
\hline S1 & Sanguine LS176 & Peach & France & AF413935 \\
\hline S2 & M7V5 & Peach & Italy & AF413936 \\
\hline S3 & M5V5 & Peach & Italy & AF413937 \\
\hline S4 & Pollizo-Liria 487 & Peach & Spain & AF413938 \\
\hline S5 & LS16 K1a & Peach & USA & AF413939 \\
\hline S6 & Pêcher 1 & Peach & USA & AF413940 \\
\hline P1 & In 21 & Peach & France & AF413941 \\
\hline $\mathrm{P} 2$ & P863 (M58152) & Plum & France & $\begin{array}{l}\text { AF413942 } \\
\text { AF413943 }\end{array}$ \\
\hline P3 & $\mathrm{P} 1713$ & Plum & France & AF413944 \\
\hline P4 & P1710 & Plum & France & AF413945 \\
\hline P5 & P3099 & Plum & France & AF413946 \\
\hline P6 & Taiyo PR72 & Plum & Japan & AF413947 \\
\hline P7 & P2172 & Plum & Japan & AF413948 \\
\hline P8 & PMB1 (AJ243438) & Plum & Germany & AF413949 \\
\hline $\mathrm{X} 2$ & RR173 & Apple & France & AF413950 \\
\hline na & P205 (D14996) & Apple & Japan & AF413951 \\
\hline na & NewSX2 & Plum & Poland & AF413952 \\
\hline na & Sunbeam Q1 & Unknown & Unknown & AF413953 \\
\hline na & $\mathrm{PO} 2$ & Unknown & Unknown & AF413954 \\
\hline na & ERM & Cherry & France & AF413955 \\
\hline
\end{tabular}

${ }^{a}$ Reference ACLSV isolates for which the genome has been fully sequenced are indicated in bold type and the relevant accession number is given in parentheses.

${ }^{\mathrm{b}}$ When two different PDO cDNA clones were sequenced, the two accession numbers are given. na, not applicable. different amplified cDNAs. All sequences were deposited in GenBank and accession numbers are provided in Tables 1 and 2. Multiple sequence alignments and phylogenetic reconstructions (neighbor-joining) were performed on a 289-nucleotide portion of the PDO fragment, which was available for all isolates/sequences, using the CLUSTALX program with randomized bootstrap evaluation of branching validity (43). Phylogenetic trees were visualized using TREEVIEW (36). Average diversities, genetic distances, and synonymous/nonsynonymous substitution rates and other phylogenetic reconstructions were calculated using Mega2 (28). Tests to evaluate the saturation of the phylogenetic signal were performed using DAMBE (50).

\section{RESULTS}

PDO amplification of tricho-, capillo-, and foveaviruses from fruit trees and sensitivity of the PDO test. CLUSTALW alignment of available full-length genomic sequences were performed in order to identify short sequences of homology in the RNA-dependent RNA polymerase (RdRp) encoding domain of viruses representative of the genera Trichovirus, Capillovirus, and Foveavirus, namely ACLSV, ASPV, ASGV, and CVA. CGRMV, formerly considered to be a tentative member of the genus Foveavirus but recently reclassified as unassigned to any genus within the family Flexiviridae, was also used. Five blocks of substantial sequence conservation were identified in this way, which correspond to the conserved motifs I, II, V, VI (so called GDD motif), and VII identified by Koonin (27) in the RdRp of positivestrand RNA viruses (Fig. 1A). Low degeneracy inosine-containing primers targeting these five regions were designed according to the following criteria: (i) inosine was preferred to degeneration for the last seven $3^{\prime}$ terminal nucleotides of the primers, (ii) inosine was preferred at positions of more than twofold degeneracy, and (iii) when possible degeneracy was further reduced by taking into account nucleotide sequence conservation between the various viruses. The sequence of these primers is given in Figure 1C.

TABLE 2. List and origin of the samples tested by polyvalent degenerate oligonucleotides (PDO) reverse transcription-polymerase chain reaction amplification, names of the viruses identified, and accession numbers of the sequences of PDO cDNA fragments

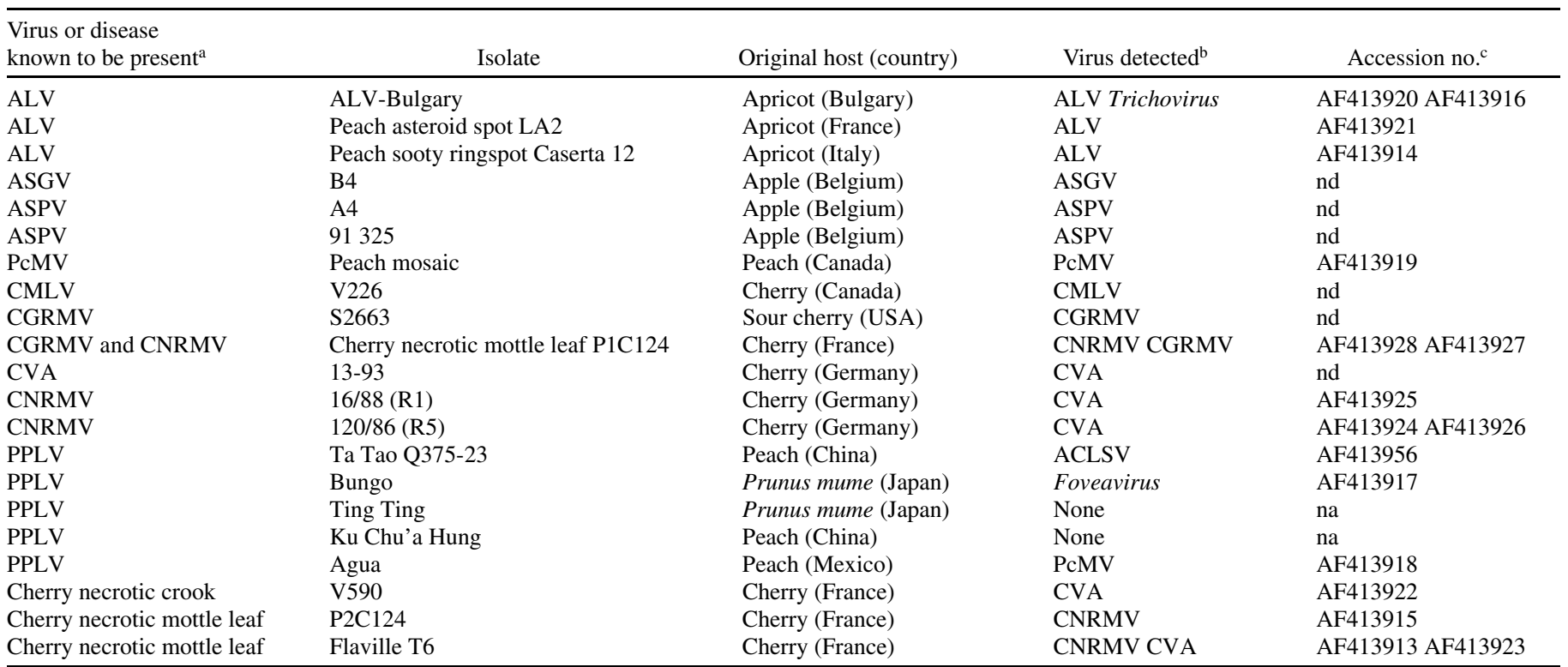

${ }^{a}$ Apricot latent virus (ALV), Apple stem grooving virus (ASGV), Apple stem pitting virus (ASPV), Peach mosaic virus (PcMV), Cherry mottle leaf virus (CMLV), Cherry green ring mottle virus (CGRMV), Cherry necrotic rusty mottle virus (CNRMV), Cherry virus A (CVA), Apple chlorotic leaf spot virus (ACLSV), and Plum pox-like virus (PPLV). PPLV denotes the presence of agents cross-reacting with Plum pox virus antisera and is tentatively named Plum pox-like virus $(20,23)$.

${ }^{b}$ If mixed infection of two agents was identified, the names of the two viruses are given and the corresponding accession numbers for the two different cDNA sequences are given.

${ }^{\mathrm{c}}$ na, not applicable; nd, not determined. 
Initial attempts to use combinations of these primers in standard RT-PCR assays indicated that although amplification of some of the target viruses could sometimes be obtained, results were frequently inconsistent and showed a general lack in sensitivity (data not shown). A nested RT-PCR test was therefore set up (PDO test) (Fig. 2), in which a combination of three primers (PDO-Fli, PDO$\mathrm{R} 3 \mathrm{i}$, and PDO-R4i) was used for the RT and first round of amplification and two internal primers (PDO-F2i and PDO-R1i) were used for the second nested amplification. As presented in Figure 2A, with the nested PDO amplification system the five targeted viruses were efficiently and reproducibly detected in peach, apple, or cherry leaf tissues, yielding the expected 362-bp PCR product.

Using ACLSV strain P863 propagated in GF305 peach seedlings as a model system, the sensitivity of the PDO test was compared with that of a DAS-ELISA or an ACLSV-specific RT-PCR detection assay (5) by testing 10-fold serial dilutions of clarified leaf homogenate (ELISA) or TNA extracts prepared from these dilutions (PCR assays). All dilutions were prepared in healthy plant homogenate. All three assays gave similar results, allowing a positive detection of the virus down to the 1/100 dilution of the extract from infected tissue (Fig. 2B).

Detection of a broad range of ACLSV isolates and analysis of ACLSV variability using PDO nested RT-PCR. Analysis of the four complete ACLSV genomic sequences available indicated that this virus shows a significant variability (16). A collection of 26 ACLSV isolates representing different hosts of isolation and different countries of origin was therefore assayed in parallel by PDO nested RT-PCR and by the A52-A53 ACLSV-specific RTPCR assay (5). A DAS-ELISA based on a polyclonal antiserum against the P863 ACLSV isolate was used as a control. The ELISA and the PDO RT-PCR detected all 26 isolates, whereas all but three isolates, namely Commun A337 (A1), Pollizo-Liria 487 (S4), and P3099 (P5), were detected by the A52-A53 RT-PCR test (data not shown). These results indicate that the PDO test showed a broader polyvalence than the previously reported ACLSVspecific assay. All PDO-amplified cDNA fragments were cloned and sequenced. In the case of the Rouge du Roussillon D08 (A4) isolate, the cDNA clone obtained diverged significantly from the other ACLSV sequences obtained (described below). However,

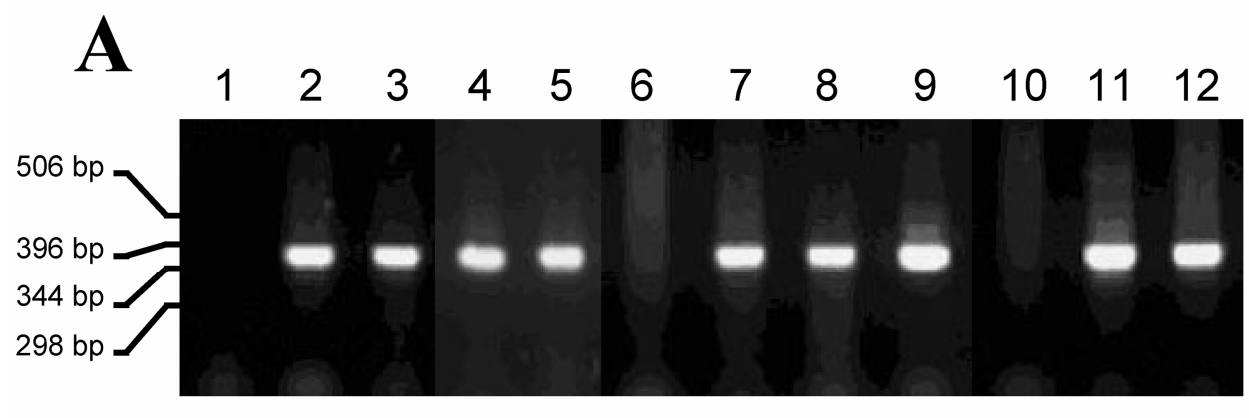

B

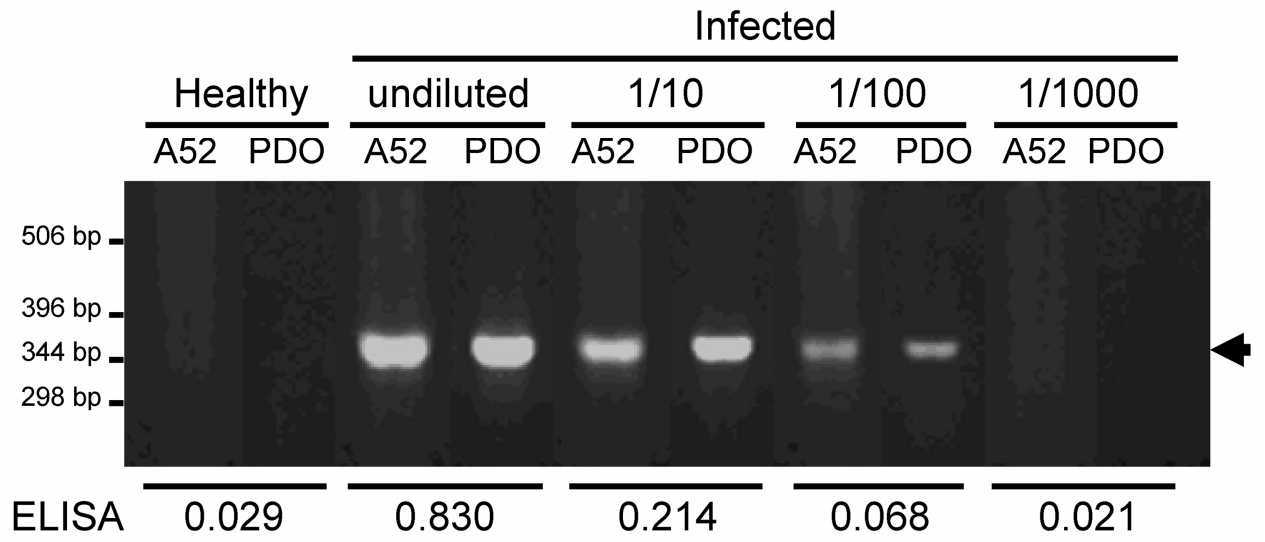

Fig. 2. Polyvalent degenerate oligonucleotides (PDO) nested reverse transcription-polymerase chain reaction (RT-PCR) detection of various tricho-, capillo-, and foveaviruses and comparison of the sensitivity with other detection assays. A, Detection by PDO RT-PCR of tricho-, capillo-, and foveaviruses in extracts from woody hosts. Lane 1, healthy GF305 peach seedling; lane 2, GF305 infected with the Apple chlorotic leaf spot virus (ACLSV, Trichovirus) plum isolate P863; lane 3, GF305 infected with the ACLSV cherry isolate Balaton; lane 4, GF305 infected with Apricot latent virus (ALV, Foveavirus) isolate Bulgary; lane 5, GF305 infected with the ALV peach asteroid spot LA2 isolate; lane 6, healthy cherry control (cv. Sam); lane 7, cv. Sam cherry infected with Cherry mottle leaf virus (CMLV, Trichovirus) isolate V226; lane 8, Sam cherry infected with Cherry green ring mottle virus (CGRMV, unassigned, Flexiviridae) isolate S2663; lane 9, Sam cherry infected with Cherry virus A (CVA, Capillovirus) isolate 13/93; lane 10, healthy apple control; lane 11, apple infected with Apple stem pitting virus (ASPV, Foveavirus) isolate 91325; and lane 12, apple infected with Apple stem grooving virus (ASGV, Capillovirus) isolate B4. The position of selected molecular weight markers is indicated on the left. B, Comparison of the sensitivities of the A52-A53 ACLSV-specific RT-PCR detection assay (noted A52) (5), of the PDO RT-PCR (noted PDO) and of a double-antibody sandwich enzyme-linked immunosorbent assay (ELISA). The first two lanes correspond to a healthy GF305 peach seedling sample. The ACLSV (plum isolate P863) infected GF305 sample was either assayed undiluted or serially diluted 10-fold in healthy GF305 extract. The position of selected molecular weight markers is indicated on the left. The positions of the 358-bp A52-A53 RT-PCR product or of the 362-bp PDO RT-PCR product are indicated by an arrow on the right. For ELISA, representative optical density values determined $1 \mathrm{~h}$ after the addition of the substrate are provided below their respective sample lanes. 
sequence analysis of a second cDNA clone obtained from the same ACLSV source propagated in Chenopodium quinoa yielded a more typical ACLSV sequence, indicating the presence in mixed infection of two divergent agents in the original A4 source.

Analysis of the sequences of the PDO fragments revealed a very high level of variability, with the average level of divergence between isolates (diversity) reaching $18.9 \%$ when considering the nucleotide sequences and $5.8 \%$ when considering the amino acid sequences. This variability is concentrated on the third base of the codons with only three of the 96 third bases on the sequenced fragment being conserved in the data set. These three bases correspond, in fact, to nondegenerate codons (one methionine and two tryptophan) so that mutations at these positions would affect the encoded protein. Further evidence that the mutations observed between isolates are concentrated on the third base of the codons comes from separate calculations of sequence diversity on all three bases, which gave values of $6.1,3.3$, and $47 \%$ for the first, second, and third bases, respectively. Most of the mutations are noncoding, as indicated by the comparison of the average genetic distances between isolates calculated for synonymous and nonsynonymous substitutions. The modified Ney-Gojobori distances are 0.579 (synonymous) and 0.040 (nonsynonymous), indicating a more than 10 -fold excess of noncoding over coding mutations.

Saturation tests indicated that the phylogenetic signal is not saturated on the first and second bases of the codons but that it is saturated on the third. Thus, using the complete sequence for phylogenetic reconstructions is not appropriate because, on the third base, there is a high risk that the presence of identical nucleotides does not reflect common ancestry but rather convergent mutations (homoplasy). This is illustrated in Figure 3 which compares phylogenetic trees obtained using the complete sequence (Fig. 3A) or only the first and second bases of the codons, which being unsaturated provide a more accurate or more meaningful phylogenetic signal (Fig. 3B). The most remarkable difference between the two trees is that when analyzing the complete sequence, CMLV clusters within the ACLSV tree, despite the fact that CMLV is clearly a distinct virus (1), while the tree reconstructed
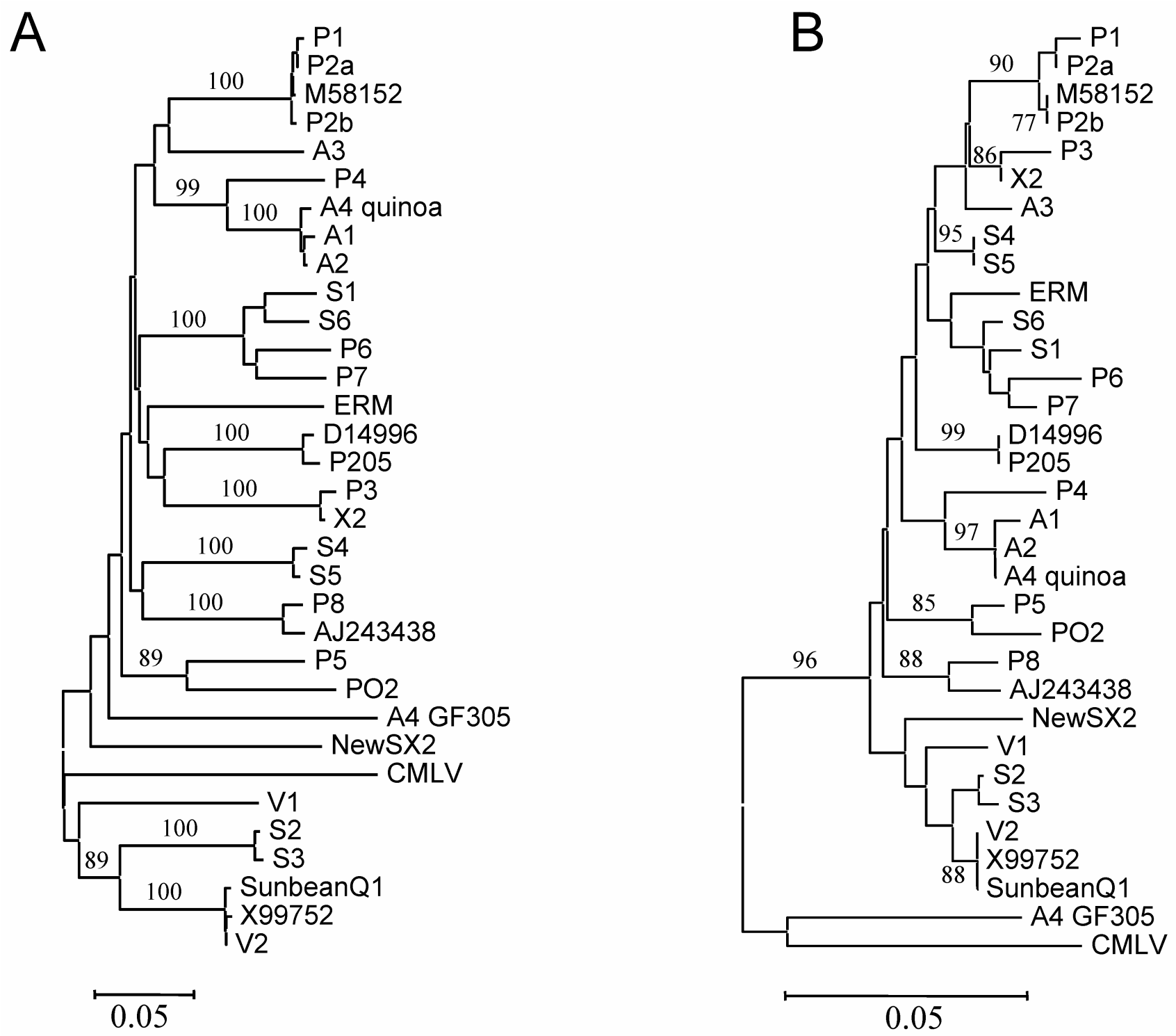

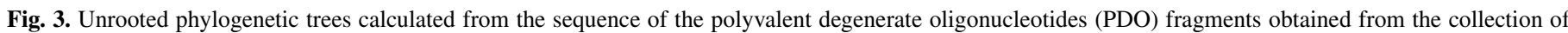

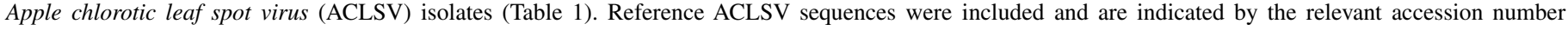

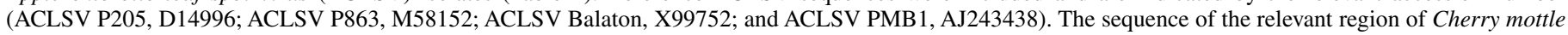

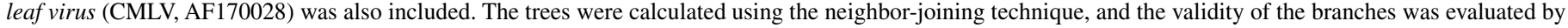

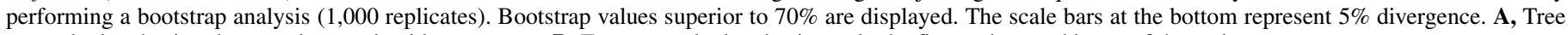
was calculated using the complete nucleotide sequences. B, Tree was calculated using only the first and second bases of the codons. 
using only the first and second bases clearly separates CMLV from ACLSV with a very high bootstrap value (similar results are obtained when reconstructing the phylogeny using the encoded amino acid sequences; data not shown). Surprisingly, the same situation applies to the sequence obtained from GF305 peach for the A4 isolate. This indicates that in addition to the ACLSV isolate whose sequence was recovered from the A4 material propagated in $C$. quinoa (A4 quinoa) and which clusters with the A1 and A2 isolates, the A4 source contains a significantly divergent agent which probably represents a distinct and new member of the genus Trichovirus.

Detection and identification of the genera Trichovirus, Capillovirus, and Foveavirus in Prunus material including virus-like peach and cherry disorders. In order to further confirm the ability of the PDO RT-PCR assay to broadly amplify tricho-, capillo-, and foveaviruses, amplifications were performed on a range of Prunus materials infected with known agents or affected by virus-like disorders of unknown etiology. A detailed list of the materials used is given in Table 2. Among the known agents were isolates of PcMV and CMLV (genus Trichovirus), CVA and ASGV (genus Capillovirus), ASPV and ALV (genus Foveavirus), and CGRMV and CNRMV (former members of the genus Foveavirus currently in the family Flexiviridae unassigned to a genus). In all cases, a positive amplification signal was obtained, further confirming the broad specificity of the PDO assay. In the case of the original ALV isolate (ALV-Bulgary) (35), evidence of a mixed infection was obtained in that two very different sequences were obtained when sequencing the amplification product (Table 2; described below). In the case of two of the CNRMV isolates, sequencing of the cloned amplified product revealed sequences with high homology to CVA, an indication of a probable mixed infection of CNRMV and CVA.

The samples analyzed also contained isolates of poorly known agents such as PPLV, a virus of unclear taxonomic status thought to be responsible for serological cross-reactions with Plum pox virus (PPV) antisera in some Prunus germ plasm of Asian origin $(19,20,23)$. The six originally described sources of this agent were investigated, namely, Bungo, Ting Ting, Ta Tao Q375-02, Ta Tao Q375-23, Ku Chu'a Hung, and Agua (20). Four of the six tested PPLV sources gave a PDO amplification product, with only Ting Ting and $\mathrm{Ku}$ Chu'a Hung failing to give a positive amplification (data not shown). The PDO cDNA products from three of these sources were cloned and sequenced, providing evidence for the presence of at least three distinct agents in these materials (described below).

Finally, Prunus materials affected by two cherry virus-like diseases of unknown etiology were also evaluated using PDO RTPCR. These included one sample affected with cherry necrotic crook disease (9) and two samples infected with cherry necrotic mottle leaf disease $(9,14)$. Again, positive amplification signals were obtained in each case (data not shown). Analysis of the amplified cDNA fragments revealed the presence of CVA in two of the samples (cherry necrotic crook V590 and cherry necrotic mottle leaf Flaville T6) and the presence of CNRMV in the two cherry necrotic mottle leaf disease samples (described below).

A phylogenetic tree reconstructed from the amino acids sequences encoded by all the cDNA fragments sequenced is shown in Figure 4. For comparison, the reference sequences present in the databanks for relevant members of the genera Trichovirus (ACLSV, CMLV), Capillovirus (ASGV, CVA), and Foveavirus (ASPV, ALV) were also included. As can be seen in Figure 4, despite its short length (96 amino acids except for ASGV which is 98 amino acids due to a 6-nucleotide in-frame insertion) the sequence encoded by the PDO cDNA fragment was a good taxonomic predictor and provided phylogenetically informative data. Indeed, all three genera were easily identified and were supported by high bootstrap values. The fact that ASGV and CVA did not cluster together (and therefore that the genus Capillovirus is likely to be polyphyletic) fit well with results derived from whole genome analysis (1). In addition, Figure 4 confirms the identification of the various amplified agents derived from sequence analysis. Several points are of particular interest in this context. The first concerns the identity of the second agent found in mixed infection in the original ALV isolate. The corresponding sequence (NT ALV in Figure 4) clustered with a high bootstrap value with the divergent sequence obtained from the multiply infected ACLSV A4 sample and probably represents a new member of the genus Trichovirus. The second point concerns the position of the sequence obtained from the PcMV sample which clustered (70\% bootstrap) with the reference CMLV sequence, confirming the relatedness of these two agents (21). The last point concerns the agents amplified by PDO from the three PPLV sources from which sequences were determined. The three agents detected had very different taxonomic positions: the Ta Tao Q375-23 sequence clustered with the ACLSV isolates (85\% bootstrap), the Agua sequence clustered with PcMV (96\% bootstrap), and the Bungo sequence fell in the genus Foveavirus cluster (99\% bootstrap) but appeared to be distinct from all previously identified agents in this genus and likely represents a new member of the genus Foveavirus.

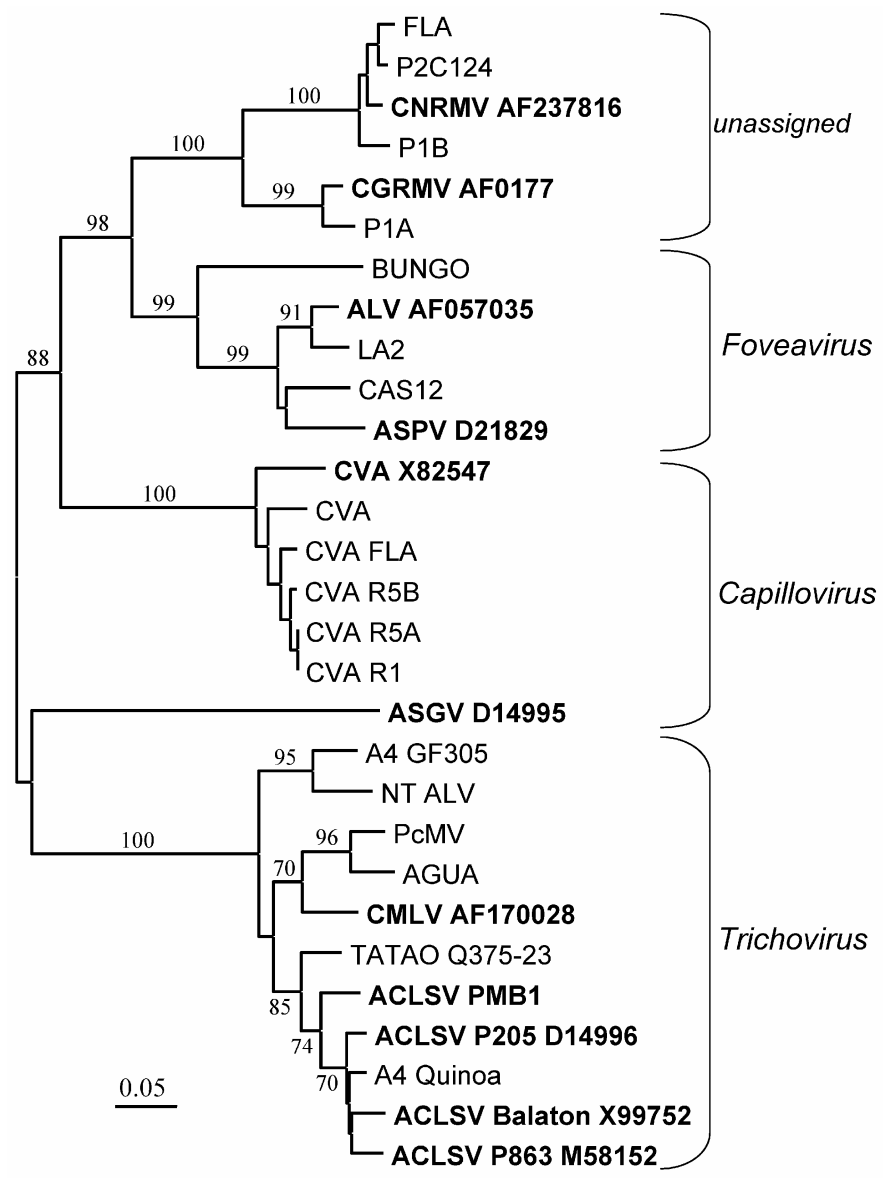

Fig. 4. Phylogenetic tree reconstructed from the amino acid sequences encoded by the polyvalent degenerate oligonucleotides (PDO) fragments obtained from a range of Prunus material including material affected by viruslike peach and cherry disorders. A precise description of the materials is presented in Table 2. The corresponding region from reference sequences present in the databanks were included in the comparison and are indicated by accession numbers. The tree was reconstructed using the neighbor-joining strategy and the branches were evaluated by bootstrap analysis $(1,000$ replicates). Bootstrap values superior to $70 \%$ are indicated. When applicable, the various genera to which the viruses belong are indicated on the right. In the case of Cherry necrotic rusty mottle virus (CNRMV) and Cherry green ring mottle virus (CGRMV), a question mark is indicated because these viruses are no longer considered to belong to the genus Foveavirus. The scale bar at the bottom represents $5 \%$ divergence. 


\section{DISCUSSION}

Contrary to other pathogens such as fungi or bacteria for which the existence of highly conserved genomic regions has allowed the development of molecular assays of very broad specificity, the extremely high variability of viral genomes both in terms of structure and in terms of sequence has generally precluded the development of nucleic acid-based detection assays to detect viruses above the species or genus level. A notable exception is the electrophoretic analysis of double-stranded RNAs (47), which has the potential to detect essentially all RNA viruses but is nevertheless limited in its practical applications due to its lack in sensitivity. With few exceptions, such as the case of the Potyviridae-specific detection assays $(6,17)$, the polyvalent PCR-based assays that have been developed thus far do not provide a detection range above the genus level. The results presented here demonstrate the feasibility of using highly degenerate, inosine-containing primers for the simultaneous detection of members of at least three viral genera in the family Flexiviridae, the Trichovirus, Capillovirus, and Foveavirus.

One of the prerequisites to such an approach is the identification of conserved genomic regions which can be targeted by the amplification primers. At the genus level and above, there are few such regions but the conserved motifs around the putative active site of the replication-associated proteins (27) offer such a possibility. Indeed, the use of primers targeting these motifs for the development of genus-specific detection assays has been reported for vitiviruses (42), carmoviruses (34), tymoviruses (41), and marafiviruses (41). Even with such highly conserved motifs, variability in the amino acid sequence and the degeneracy of the genetic code can still necessitate the use highly degenerate oligonucleotides. In the work reported here, allowing for all possibilities would result in oligonucleotides of between 24,576-fold (R3i) and 65,536-fold degeneracy (F1i). Introduction of a few restrictive hypotheses and the use of inosines, which can base pair with any nucleotide, reduce the degeneracy of the oligonucleotides down to between 16-fold (R3i) and 256-fold (F1i). With this level of degeneracy, the sensitivity of the PCR is still significantly reduced but this can be compensated by the use of a nested procedure which provides for the efficient amplification of the target viruses. This effect may also explain why the sensitivity of the detection of ACLSV using the PDO assay appears to be in the same range as the sensitivity of the direct RT-PCR A52-A53 assay when nested PCR assays using nondegenerate primers are usually reported to significantly increase the sensitivity over direct PCR assays (30).

The sensitivity of the PDO assays should, however, prove sufficient for most diagnostic or characterization purposes using infected Prunus material. There seems to be, however, a potential limitation to the sensitivity of detection in the case of mixed infections. For example, in the A4 isolate, ACLSV was only detected after transmission to an alternative herbaceous host, C. quinoa, whereas direct PDO detection in the original GF305 peach seedlings only revealed the presence of a new Trichovirus. In other cases of samples known to have multiple infections, detection by PDO gave variable results: in some cases amplification of the two agents was observed (for example, co-detection of CGRMV and CNRMV in the P1C124 cherry necrotic mottle leaf sample), while in other cases only one of the agents was detected. This effect likely reflects differential accumulation of the agents present and/or competition between the various cDNAs during the amplification process. Since identification of the viruses amplified relies on the sequencing of amplification products, in most cases an agent representing less than 10 to $20 \%$ of the bulk of the amplified material would probably not have been detected upon sequencing of the uncloned PCR product. Care should therefore be taken when interpreting results of a PDO-PCR when a positive is obtained for a virus, because other viruses could be present but not detected. Further improvement of PDO sensitivity as well as simultaneous identification of the virus genus or species amplified should be possible with the use of genus- or species-specific molecular fluorescent probes.

Despite its current potential limitations, the PDO assay demonstrated its polyvalence for the detection of genera Foveavirus, Capillovirus, and Trichovirus. Efforts to evaluate the possibility to amplify other members of the family Flexiviridae with this assay have met with mixed results; no amplification was obtained in the cases of several vitiviruses or allexiviruses but positive results were obtained with BanMMV (13) and with a seemingly new virus in banana (unpublished data). Sequence comparisons of the targeted polymerase motifs are in agreement with these results and indicate that two other unclassified viruses in the family are probably detectable by PDO PCR, SCSMaV (45) and CLBV (12). The same comparisons indicate that the amplification of potexviruses is very unlikely but that amplification of carlaviruses is a strong possibility that remains to be evaluated.

In etiology, characterization, and variability studies, PDO RTPCR has proven to be a useful tool. Its potential to detect previously unknown agents should be of particular interest. In this study, a relatively limited number of samples affected by diseases of unknown etiology were evaluated and the presence of poorly known viruses or of seemingly new members of the genera Trichovirus and Foveavirus was demonstrated. It is too soon to speculate on a potential role of these agents in the diseases affecting the plants from which they were isolated, since they were frequently observed in mixed infection with other viruses. However, some hypotheses can already be drawn from the available data in a few situations. In particular, the systematic detection of CNRMV in cherry material affected by the cherry necrotic mottle leaf disease clearly suggests a causal role for this virus while the detection of the new Foveavirus in only one (Bungo) of the six evaluated sources of PPLV seems to rule out the responsibility of this new agent in the observed serological cross-reactions with PPV antisera (20). The sequences of the PDO PCR products provide the information to develop PCR assays specific for these agents. These new assays should help to investigate the prevalence of these new viruses in fruit trees and to unravel the precise relationships between these new or poorly known viruses and the various diseases studied.

\section{ACKNOWLEDGMENTS}

This work was funded by the European community project FAIR5 contract no. CT97-3889. We thank W. Jelkmann and M. Rott (BBA, Institut fur Pflanzenschutz im Obstbau, Dossenheim, Germany), J. Kummert (Faculté des Sciences Agronomiques de Gembloux, Belgium), D. James (Centre for Plant Health, Canadian Food Inspection Agency, Sidney, BC, Canada), and A. Hadidi (USDA, Beltsville, MD) for viral isolates and samples of plants infected with known and unknown agents; and K. Mayo for improving the English of the manuscript.

\section{LITERATURE CITED}

1. Adams, M. J., Antoniw, J. F., Bar-Joseph, M., Brunt, A. A., Candresse, T., Foster, G. D., Martelli, G. P., Milne, R. G., and Fauquet, C. M. 2004. The new plant virus family Flexiviridae and assessment of molecular criteria for species demarcation. Arch. Virol. 149:1045-1060.

2. Boom, R., Sol, C. J. A., Salimans, M. M. M., Jansen, C. L., Wertheim van Dillen, P. M. E., and van der Noordaa, J. 1990. Rapid and simple method for purification of nucleic acids. J. Clin. Microbiol. 28:495-503.

3. Brown, J. K. 2000. Molecular markers for the identification and global tracking of whitefly vector-Begomovirus complexes. Virus Res. 71:233-260.

4. Candresse, T., Hammond, R. W., and Hadidi, A. 1998. Detection and identification of plant viruses and viroids using polymerase chain reaction (PCR). Pages 399-416 in: Plant Virus Disease Control. A. Hadidi, R. K. Khetarpal, and H. Koganezawa, eds. The American Phytopathological Society, St. Paul, MN.

5. Candresse, T., Lanneau, M., Revers, F., Grasseau, N., Macquaire, G., German, S., Malinovsky, T., and Dunez, J. 1995. An immunocapture PCR 
assay adapted to the detection and the analysis of the molecular variability of the apple chlorotic leafspot virus. Acta Hortic. 386:136-147.

6. Chen, J., Chen, J., and Adams, M. J. 2001. A universal PCR primer to detect members of the Potyviridae and its use to examine the taxonomic status of several members of the family. Arch. Virol. 146:757-766.

7. Choi, S. K., Choi, J. K., Park, W. M., and Ryu, K. H. 1999. RT-PCR detection and identification of three species of cucumoviruses with a genus-specific single pair of primers. J. Virol. Methods 83:67-73.

8. Colinet, D., Kummert, J., Lepoivre, P., and Semal, J. 1993. Identification of distinct potyviruses in mixedly-infected sweetpotato by the polymerase chain reaction with degenerate primers. Phytopathology 84:65-69.

9. Desvignes, J. C., Boyé, R., Cornaggia, D., and Grasseau, N. 1999. Virus Diseases of Fruit Trees. Ctifl, Paris, France.

10. Dovas, C. I., Efthimiou, K., and Katis, N. I. 2004. Generic detection and differentiation of tobamoviruses by a spot-nested RT-PCR-RFLP using dIcontaining primers along with homologous dG-containing primers. J. Virol. Methods 117:137-144.

11. Foissac, X., Svanella-Dumas, L., Dulucq, M. J., Gentit, P., and Candresse, T. 2001. Polyvalent detection of fruit tree tricho, capillo and foveaviruses by nested RT-PCR using degenerated and inosine containing primers (PDO RT-PCR). Acta Hortic. 550:37-43.

12. Gallipienso, L.,Vives, M. C., Moreno, P., Milne, R. G., Navarro, L., and Guerri, J. 2001. Partial characterization of Citrus leaf blotch virus, a new virus from Nagami kumquat. Arch. Virol. 146:357-368.

13. Gambley, C. F., and Thomas, J. E. 2001. Molecular characterization of Banana mild mosaic virus, a new filamentous virus in Musa spp. Arch. Virol. 146:1369-1379.

14. Gentit, P., Foissac, X., Svanella-Dumas, L., Peypelut, M., Macquaire, G., and Candresse, T. 2002. Molecular characterization of foveaviruses associated with the cherry necrotic mottle leaf disease and complete sequencing of a Cherry green ring mottle virus European isolate. Arch. Virol. 147:1033-1042.

15. German, S., Candresse, T., Lanneau, M., Huet, J. C., Pernollet, J. C., and Dunez, J. 1990. Nucleotide sequence and genomic organization of apple chlorotic leaf spot closterovirus. Virology 179:104-112.

16. German-Retana, S., Bergey, B., Delbos, R. P., Candresse, T., and Dunez, J. 1997. Complete nucleotide sequence of the genome of a severe cherry isolate of Apple chlorotic leafspot Trichovirus (ACLSV). Arch. Virol. 142:833-841.

17. Gibbs, A., and Mackenzie, A. 1997. A primer pair for amplifying part of the genome of all potyvirids by RT-PCR. J. Virol. Methods 63:9-16.

18. Gibbs, A. J., Mackenzie, A. M., and Gibbs, M. J. 2003. The "potyvirids primers" will probably provide phylogenetically informative DNA fragments from all species of Potyviridae. J. Virol. Methods 112:41-44.

19. Hari, V., Abdel-Ghaffar, H., Levy, L., and Hadidi, A. 1995. Asian Prunus latent virus: An unusual Potyvirus detected in germplasm from east Asia. Acta Hortic. 386:78-85.

20. James, D., Godkin, S. E., Eastwell, K. C., and Mackenzie, D. J. 1996. Identification of Prunus virus isolates that cross-react with Plum pox virus and Apple stem pitting virus antisera. Plant Dis. 80:536-543.

21. James, D., and Howell, W. E. 1998. Isolation and partial characterization of a filamentous virus associated with peach mosaic disease. Plant Dis. 82:909-913.

22. James, D., Jelkmann, W., and Upton, C. 2000. Nucleotide sequence and genome organisation of Cherry mottle leaf virus and its relationship to members of the Trichovirus genus. Arch. Virol. 145:995-1007.

23. James, D., Thompson, D. A., and Godkin, S. E. 1994. Cross reactions of an antiserum to plum pox potyvirus. OEPP/EPPO Bull. 24:605-614.

24. Jelkmann, W. 1994. Nucleotide sequence of Apple stem pitting virus and of the coat protein of similar virus associated with vein yellows disease and their relationship with potex- and carlaviruses. J. Gen. Virol. 75:15351542 .

25. Jelkmann, W. 1995. Cherry virus A: cDNA cloning of dsRNA, nucleotide sequence analysis and serology reveal a new plant Capillovirus in sweet cherry. J. Gen. Virol. 76:2015-2024.

26. Karasev, A. V., Nikolaeva, O. V., Koonin, E. V., Gumpf, D. J., and Garnsey, S. M. 1994. Screening of the closterovirus genome by degenerate primermediated polymerase chain reaction. J. Gen. Virol. 75:1415-1422.

27. Koonin, E. V. 1991. The phylogeny of RNA-dependent RNA polymerases of positive-strand RNA viruses. J. Gen. Virol. 72:2197-2206.

28. Kumar, S., Tamura, K., Jakobsen, I. B., and Nei, M. 2001. MEGA2: Molecular evolutionary genetics analysis software. Bioinformatics 17:12441245

29. Langeveld, S. A., Dore, J. M., Memelink, J., Derks, A. F., van der Vlugt, C. I. M., Asjes, C. J., and Bol, J. F. 1991. Identification of potyviruses using the polymerase chain reaction with degenerate primers. J. Gen. Virol. 72:1531-1541
30. Lopez, M. M., Bertolini, E., Olmos, A., Caruso, P., Gorris, M. T., Llop, P., Penyalver, R., and Cambra, M. 2003. Innovative tools for detection of plant pathogenic viruses and bacteria. Int. Microbiol. 6:233-243.

31. Maliogka, V., Dovas, C. I., Efthimiou, K., and Katis, N. I. 2004. Detection and differentiation of Comoviridae species using a semi-nested RTPCR and a phylogenetic analysis based on the polymerase protein. J. Phytopathol. 152:404-409.

32. Martelli, G., Candresse, T., and Namba, S. 1994. Trichovirus, a new genus of plant viruses. Arch. Virol. 134:451-455.

33. Martelli, G. P., and Jelkmann, W. 1998. Foveavirus, a new plant virus genus. Arch. Virol. 143:1245-1249.

34. Morozov, S. Y., Ryabov, E. V., Leiser, R. M., and Zavriev, S. K. 1995. Use of highly conserved motifs in plant virus RNA polymerases as the tags for specific detection of Carmovirus-related RNA-dependent RNA polymerase genes. Virology 207:312-315.

35. Nemchinov, L. G., Shamloul, A. M., Zemtchik, E. Z., Verderevskaya, T. D., and Hadidi, A. 2000. Apricot latent virus: A new species in the genus Foveavirus. Arch. Virol. 145:1801-1813.

36. Page, R. D. 1996. TREEVIEW: An application to display phylogenetic trees on personal computers. Comput. Appl. Biosci. 12:357-358.

37. Pappu, S. S., Brand, R., Pappu, H. R., Rybicki, E. P., Gough, K. H., Frenkel, M. J., and Niblett, C. L. 1993. A polymerase chain reaction method adapted for selective amplification and cloning of $3^{\prime}$ sequences of potyviral genomes: Application to Dasheen mosaic virus. J. Virol. Methods 41:9-20.

38. Rojas, M. R., Gilbertson, R. L., Russel, D. R., and Maxwell, D. P. 1993. Use of degenerate primers in the polymerase chain reaction to detect whitefly-transmitted geminiviruses. Plant Dis. 77:340-347.

39. Rott, M. E., and Jelkmann, W. 2001. Complete nucleotide sequence of Cherry necrotic rusty mottle virus. Arch. Virol. 146:395-401.

40. Routh, G., Zhang, Y.-P., Saldarelli, P., and Rowhani, A. 1998. Use of degenerate primers for partial sequencing and RT-PCR-based assays of grapevine leafroll-associated viruses 4 and 5. Phytopathology 88:12381243.

41. Sabanadzovic, S., Abou-Ghanem, N., Castellano, M. A., Digiaro, M., and Martelli, G. P. 2000. Grapevine fleck virus-like viruses in Vitis. Arch. Virol. 145:553-565.

42. Saldarelli, P., Rowhani, A., Routh, G., Minafra, A., and Digiaro, M. 1998. Use of degenerate primers in a RT-PCR assay for the identification and analysis of some filamentous viruses, with special reference to clostero- and vitiviruses of the grapevine. Eur. J. Plant Pathol. 104:945950.

43. Thompson, J. D., Higgins, D. G., and Gibson, T. J. 1994. CLUSTAL W: Improving the sensitivity of progressive multiple sequence alignment through sequence weighting, positions-specific gap penalties and weight matrix choice. Nucleic Acids Res. 22:4673-4680.

44. Thompson, K. G., Dietzgen, R. G., Thomas, J. E., and Teakle, D. S. 1996. Detection of pineapple bacilliform virus using the polymerase chain reaction. Ann. Appl. Biol. 129:57-69.

45. Thompson, N., and Randles, J. W. 2001. The genome organisation and taxonomy of Sugarcane striate mosaic associated virus. Arch. Virol. 146:1441-1451.

46. Tian, T., Klaassen, V. A., Soong, J., Wisler, G., Duffus, J. E., and Falk, B. W. 1996. Generation of cDNAs specific to Lettuce infectious yellows closterovirus and other whitefly-transmitted viruses by RT-PCR and degenerate oligonucleotide primers corresponding to the Closterovirus gene encoding the heat shock protein 70 homologue. Phytopathology $86: 1167-1173$

47. Valverde, R. A., Dodds, J. A., and Heick, J. A. 1986. Double-stranded ribonucleic acid from plants infected with viruses having elongated particles and undivided genomes. Phytopathology 76:459-465.

48. van Regenmortel, M. H. V., Fauquet, C. M., Bishop, D. H. L., Carstens, E. B., Estes, M. K., Lemon, S. M., Maniloff, J., Mayo, M.A., McGeoch, D. J., Pringle, C. R., and Wickner, R. B. 2000. Virus Taxonomy, Seventh Report of the International Committee on Taxonomy of Viruses. Academic Press, New York.

49. Willment, J. A., Martin, D. P., and Rybicki, E. P. 2001. Analysis of the diversity of African streak mastreviruses using PCR-generated RFLPs and partial sequence data. J. Virol. Methods 93:75-87.

50. Xia, X., and Xie, Z. 2001. DAMBE: Data analysis in molecular biology and evolution. J. Hered. 92:371-373.

51. Yoshikawa, N., Sasaki, E., Kato, M., and Takahashi, T. 1992. The nucleotide sequence of Apple stem grooving capillovirus genome. Virology 191:98-105.

52. Zhang, Y. P., Kirkpatrick, B. C., Smart, C. D., and Uyemoto, J. K. 1998. cDNA cloning and molecular characterization of Cherry green ring mottle virus. J. Gen. Virol. 79:2275-81. 